\title{
Analisis Internet Group Management Protocol (IGMP) Menggunakan Software Wireshark dalam Layanan Live Streaming IPTV pada Multi Service Access Network (MSAN) di Area Darmo, Surabaya
}

\author{
Filda Ayu Afrida ${ }^{1}$, Suci Rahmatia ${ }^{1}$ \\ ${ }^{1}$ Program Studi Teknik Elektro, Fakultas Sains dan Teknologi, Universitas Al Azhar Indonesia \\ Komplek Masjid Agung Al Azhar Kebayoran Baru, Jakarta Selatan, 12110
}

Penulis untuk Korespondensi/E-mail: fildaayuafrida@gmail.com,suci@uai.ac.id

\begin{abstract}
Abstrak - Internet Protocol Television (IPTV) dengan data real time sangat sensitif terhadap paket yang hilang dan terlambat jika koneksi IPTV tidak begitu cepat. IPTV menggunakan Internet Protocol (IP) melewati jaringan broadband untuk pengiriman sinyal televisi digital yang mempunyai kecepatan data tinggi. Pengamatan dan analisa lebih fokus pada pengukuran live streaming dan pengambilan data secara real time di area Darmo, Surabaya. Pengukuran tersebut meliputi pengambilan data melalui aplikasi VLC Media Player dengan bantuan capture software wireshark dan implementasi layanan IPTV berbasis Internet Group Management Protocol (IGMP). Layanan IPTV ini menggunakan data realtime yaitu waktu live streaming, source, destination, protocol, dan length.
\end{abstract}

Abstract - Internet Protocol Television (IPTV) with real time data is very sensitive to lost and late packets if the IPTV connection is not so fast. IPTV uses Internet Protocol (IP) over broadband networks to transmit digital television signals that have high data rates. Observation and analysis focus more on live streaming measurements and data retrieval in real time in the Darmo area, Surabaya. These measurements include taking data through the VLC Media Player application with the help of capture Wireshark software and implementing IPTV services based on Internet Group Management Protocol (IGMP). This IPTV service uses realtime data, ie live streaming time, source, destination, protocol, and length.

Keywords - IPTV, IGMP, software wireshark, bandwith

\section{PENDAHULUAN}

$\mathrm{G}$ aya hidup masyarakat modern telah bergeser seiring perkembangan teknologi, salah satunya dalam menonton televisi (TV). Dahulu ketika ingin menonton harus menggunakan perangkat TV yang ada dirumah, namun saat ini masyarakat dapat menonton dari handphone, laptop atau desktop yang terhubung dengan internet. Layanan televisi berbasis internet ini menggunakan platform Internet Protokol TV (IPTV). IPTV adalah suatu sistem yang mengirimkan layanan multimedia seperti televisi, video, audio, text, grafik dan data yang disalurkan melalui jaringan berbasis internet protocol. IPTV tidak bergantung pada Internet dalam pengiriman layanannya, tetapi hanya terhubung ke jaringan yang berbasis IP. [1]
Penelitian ini mengambil studi kasus di area Darmo, Surabaya ini dilakukan implementasi sebuah layanan IPTV berbasis protokol Internet Group Management Protocol (IGMP) dengan menggunakan software Wireshark pada perangkat Multi Service Access Network (MSAN). Hasil implementasi layanan IPTV ini dianalisa dengan memperhatikan keadaan bandwidth pada saat pengukuran dan live video streaming.

\section{TINJAUAN PUSTAKA}

Multi Service Access Network (MSAN) ZXMSG 5200

ZXMSG 5200 adalah MSAN generasi baru yang menyediakan layanan triple-play seperti suara, data 
dan video. MSAN ini mengintegrasikan fungsi Digital Loop Carrier (DLC), IP DSLAM, nextgeneration Voice over IP (VoIP) media gateway dan Passive Optical Network (xPON) pada satu platform. Teknologi ini merupakan media penghubung antara teknologi lama dengan teknologi masa depan yang berfungsi untuk mengkonversikan cahaya menjadi listrik.

ZXMSG 5200 terletak di lapisan akses jaringan NGN/IMS. Teknologi ini dapat beradaptasi dengan jaringan PSTN/ ISDN tradisional dan dapat memenuhi tuntutan multi-layanan dari berbagai pelanggan secara efisien. ZXMSG 5200 menawarkan strategi yang ideal untuk migrasi dari layanan suara dan data berbasis TDM ke IP [2].

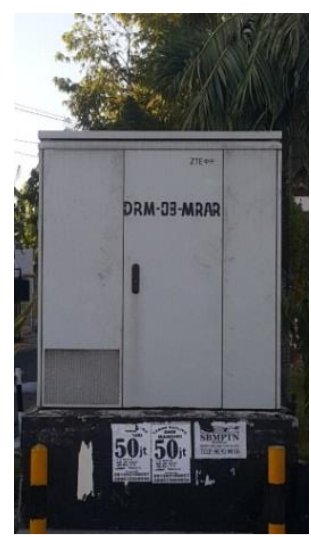

Gambar 1. MSAN ZTE ZXMSG 5200
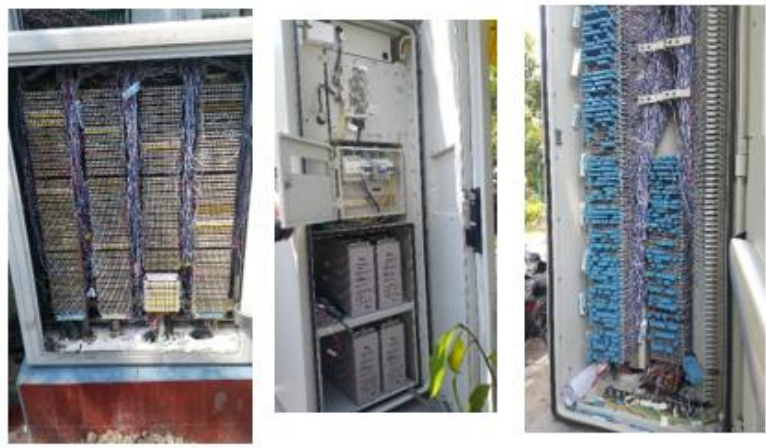

Gambar 2. Arsitektur MSAN

\section{Internet Protocol Television (IPTV)}

IPTV merupakan layanan televisi dengan jaringan internet yang menggunakan arsitektur jaringan dan metode suite protokol internet melalui paketswitched jaringan infrastruktur, misalnya, Internet dan jaringan Internet akses broadband. IPTV tidak menggunakan frekuensi radio, sinyal satelit, dan televisi kabel. Internet Protocol Television merupakan sistem transmisi televisi digital menggunakan protocol internet (IP) yang melewati infrastruktur jaringan IP dengan pita lebar. Pita lebar (broadband) dibutuhkan untuk mengirimkan format gambar bergerak dengan kualitas yang baik dan real time. [3]

\section{Internet Group Management Protocol (IGMP)}

IGMP merupakan salah satu protokol jaringan dalam kumpulan protokol Transmission Control Protocol / Internet Protocol (TCP/IP) yang bekerja pada lapisan jaringan untuk menginformasikan router-router IP tentang keberadaan group-group jaringan multicast. Apabila sebuah router mengetahui bahwa terdapat beberapa host dalam jaringan terhubung secara lokal yang tergabung ke dalam group multicast tertentu, router akan menyebarkan informasi dengan menggunakan protokol IGMP kepada router lainnya dalam sebuah internetwork sehingga pesan-pesan multicast diteruskan ke router yang sesuai. IGMP kemudian digunakan untuk memelihara keanggotaan group multicast di dalam subnet lokal untuk sebuah alamat IP multicast [4].

\section{Bandwidth}

Bandwidth adalah besaran yang menunjukkan seberapa banyak data yang dapat dilewatkan dalam koneksi melalui sebuah network. Bandwidth ini menunjukkan kemampuan maksimum dari suatu alat untuk menyalurkan informasi dalam satuan waktu biasanya dilambangkan dengan bit per detik atau dengan denominasi bit yang lebih besar seperti Megabit per detik [5]. Dikenal juga dengan perbedaan atau interval, antara batas teratas dan terbawah dari suatu frekuensi gelombang transmisi dalam suatu kanal komunikasi.

\section{Multicast}

Multicast adalah proses mengirim paket data audio atau video pada waktu yang bersamaan kepada banyak pengguna layanan audio atau video. Semua pelanggan akan menerima sinyal yang sama pada waktu yang sama. Multicast biasa disebut sebagai point to multi-point.

Keunggulan dalam penggunaan multicast, sebagai berikut:

a. Meringankan beban kerja host, karena tidak perlu melakukan replika data.

b. Kebutuhan bandwith tidak bergantung pada jumlah host. Seberapa jumlah host yang terlibat, bandwith yang dibutuhkan akan tetap sama. 
Kelemahan dalam penggunaan multicast, sebagai berikut:

a. Memerlukan standar baru pada suatu protokol IP dan protokol data layer agar bisa mengirim dan menerima data.

b. Perlu menggunakan mekanisme protokol baru untuk mengatur alokasi multicast sebagai group dalam suatu jaringan.

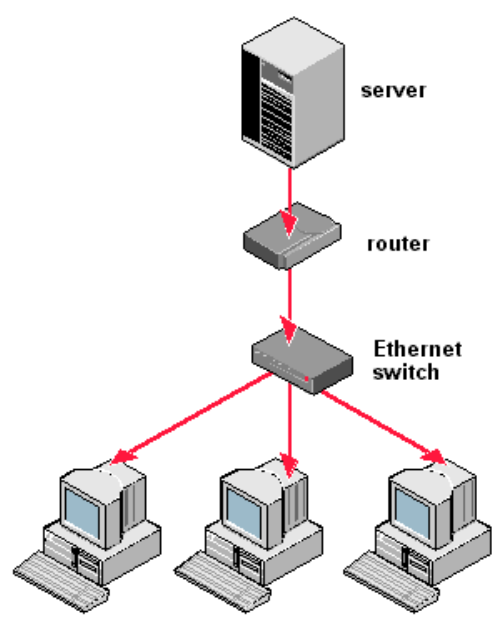

Gambar 3. Pengiriman data dengan menggunakan multicast [6]

\section{Wireshark}

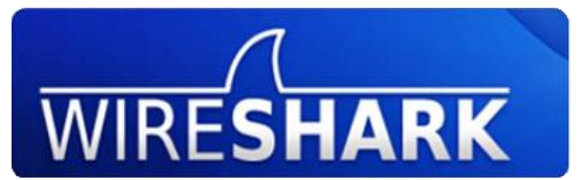

Gambar 4. Logo Wireshark [7]

Wireshark adalah tool yang digunakan untuk menganalisa paket data dalam sebuah kinerja jaringan. Wireshark dapat menangkap paket data atau informasi yang berada di dalam jaringan, sehingga data yang tertangkap dapat di analisa untuk berbagai keperluan seperti:

- Masalah dalam jaringan

- Memeriksa keamanan jaringan

- Data-data yang bersifat pribadi.

Wireshark memliki pengawasan paket data secara real time. Aplikasi wireshark dapat diakses secara gratis dan dapat dijalankan di beberapa platform seperti linux, mac dan windows.

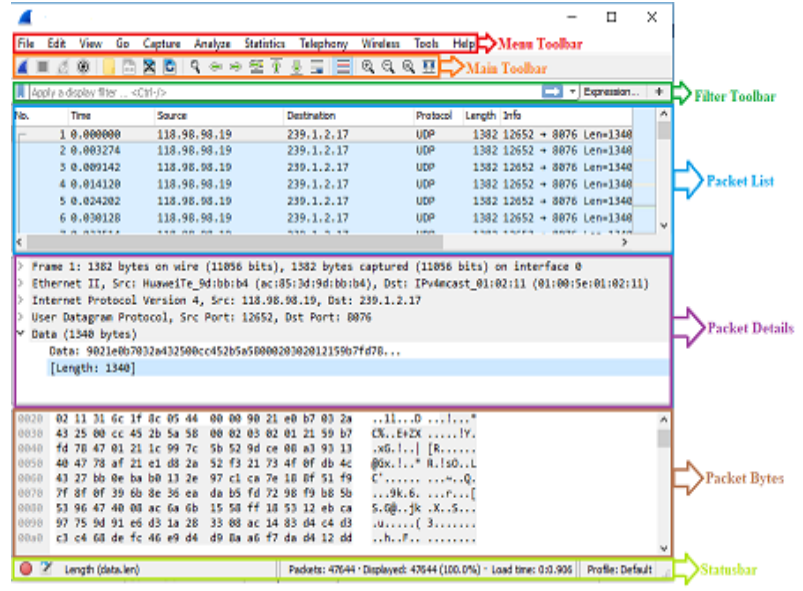

Gambar 5. Struktur Wireshark

Struktur pada wireshark:

a. Menu Toolbar: daftar tool yang digunakan untuk tindakan pada wireshark.

b. Main Toolbar: akses cepat pada item yang sering digunakan dari menu toolbar

c. Filter Toolbar: untuk memilih karakteristik filter pada paket data yang diinginkan

d. Packet List: menampilkan isi paket yang tertangkap secara ringkas

e. Packet Details: menampilkan rincian daftar paket secara lebih rinci

f. Packet Byte: Menampilkan data paket saat ini.

g. Status Bar: menampilkan pesan suatu informasi.

\section{VLC Media Player}

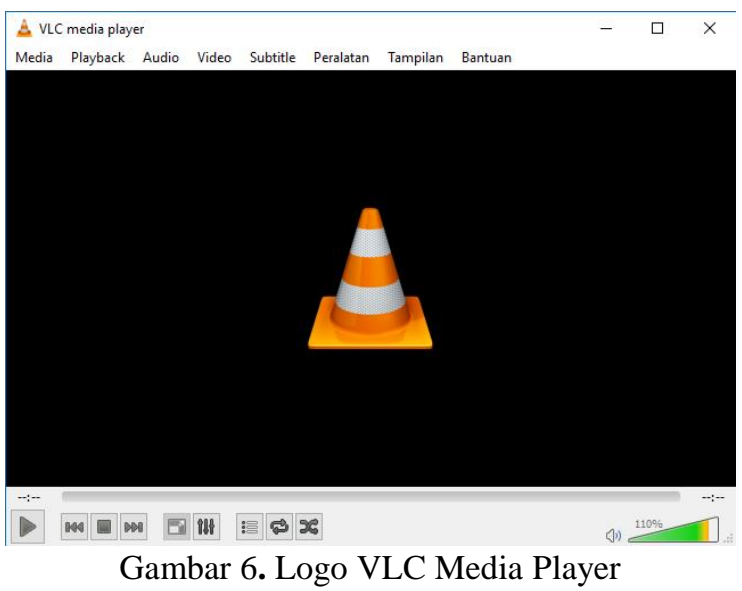

Video Lan Client (VLC) media player pertama kali dibuat di tahun 1998, kemudian dikembangkan oleh perusahaan VideoLAN. VLC adalah sebuah perangkat lunak (software) yang biasa digunakan untuk memutar video maupun audio. VLC juga dapat digunakan untuk memutar DVD, VCD, maupun CD. Perangkat lunak ini memiliki kelebihan yaitu: program yang ringan, cepat, 
beragam format file video maupun audio dapat diputar, dapat dioperasikan pada berbagai sistem operasi dan mudah di instal dengan portable eksternal, seperti di USB flash disk dan smartphone. Program VLC Media Player banyak diaplikasikan dan digunakan oleh kalangan pengguna komputer.

\section{METODE PENELITIAN}

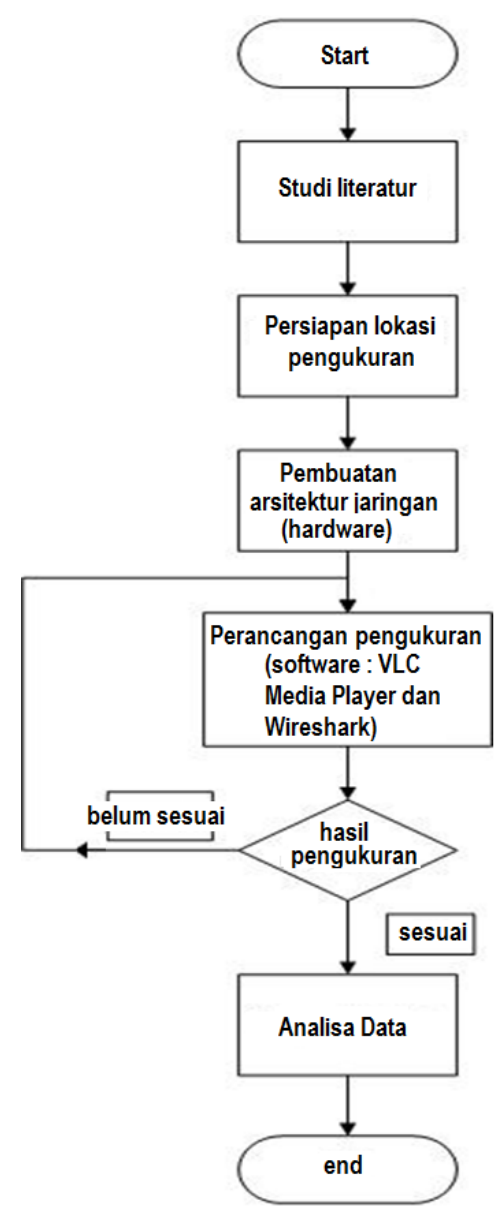

Gambar 7. Alur penelitian

Penelitian dimulai dari studi literatur untuk mempelajari dan menentukan dasar - dasar teori yang akan digunakan, Kemudian menentukan lokasi yang akan dilakukan pengukuran, dalam hal ini tempat pengukuran akan dijadikan sebagai pengambilan data live video streaming secara real time. Langkah selanjutnya adalah pembuatan arsitektur jaringan dengan perangkat hardware yang terdiri dari MSAN, TP_LINK, Laptop, kabel koneksi internet dan stopwatch. Perancangan pengukuran menggunakan beberapa software pendukung yaitu: VLC media player dan wireshark.
Perancangan kali ini akan mengambil live video streaming yang akan dibandingkan pada saat menggunakan protocol IGMP dan tidak menggunakan IGMP (protocol TCP). Setelah itu hasil data pengukuran yang diperoleh, dicek apakah sudah sesuai dengan url dan protocol yang digunakan. Bila hasil data pengukuran sudah sesuai dengan url dan protocol yang digunakan maka langsung ke tahap menganalisis data, namun bila hasil data pengukuran belum sesuai, maka perlu adanya pengambilan data ulang sampai url dan protocol sesuai dengan yang diharapkan.

\section{Langkah-Langkah Pengambilan Data}

1. Pengambilan data VLC Media Player untuk streaming:

a. Buka aplikasi VLC Media Player

b. Pilih media kemudian klik stream perangkat.

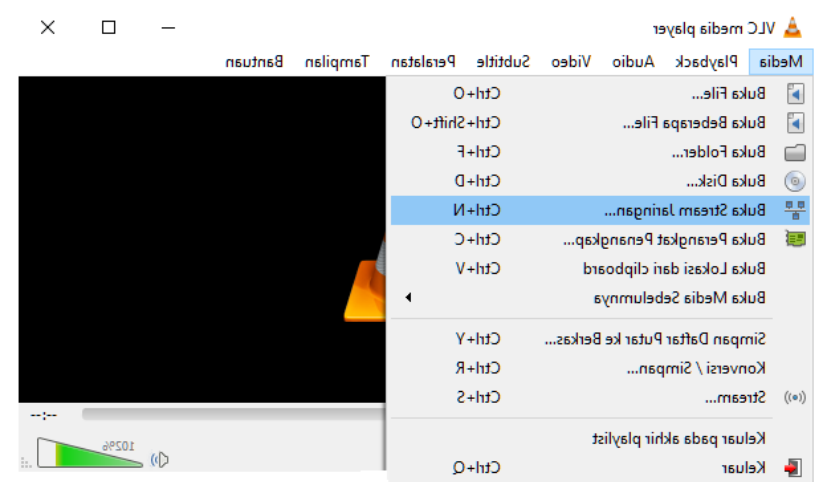

Gambar 8. Tools VLC Media Player [8]

c. Masukkan alamat rtp:// 239.1.2.91:8520. Alamat terebut merupakan yang akan digunakan live streming pada siaran program TV di Indonesia.

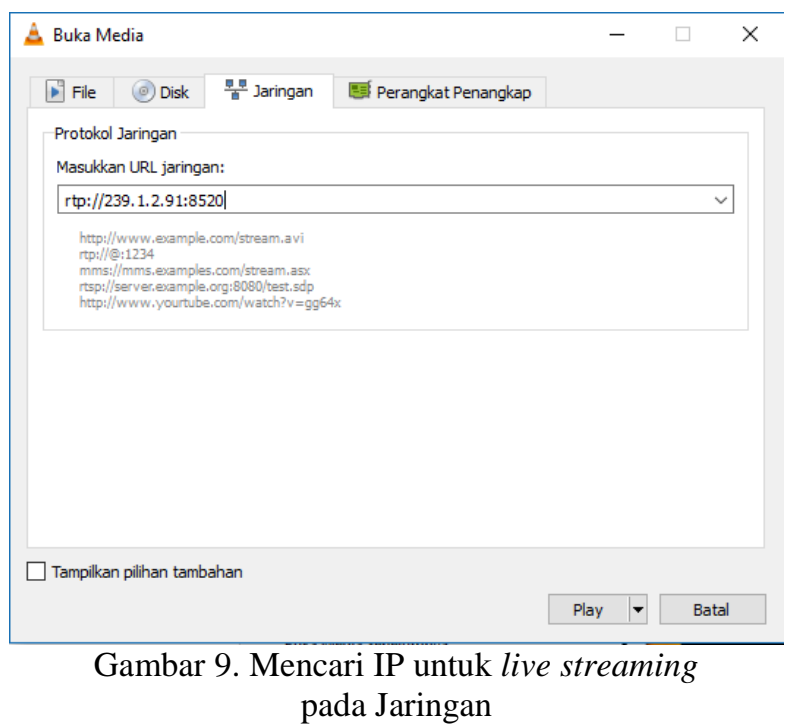


2. Pengambilan data wireshark untuk capture hasil live streaming. Pengukuran trafik menggunakan aplikasi wireshark dilakukan selama 3 menit dengan menggunakan alamat RTP 239.1.2.91:8520. Berikut langkah-langkah pengambilan capture dengan menggunakan aplikasi wireshark.

a. Buka aplikasi wireshark untuk mengcapture data yang diperoleh.

b. Kemudian akan muncul perintah seperti dibawah ini:

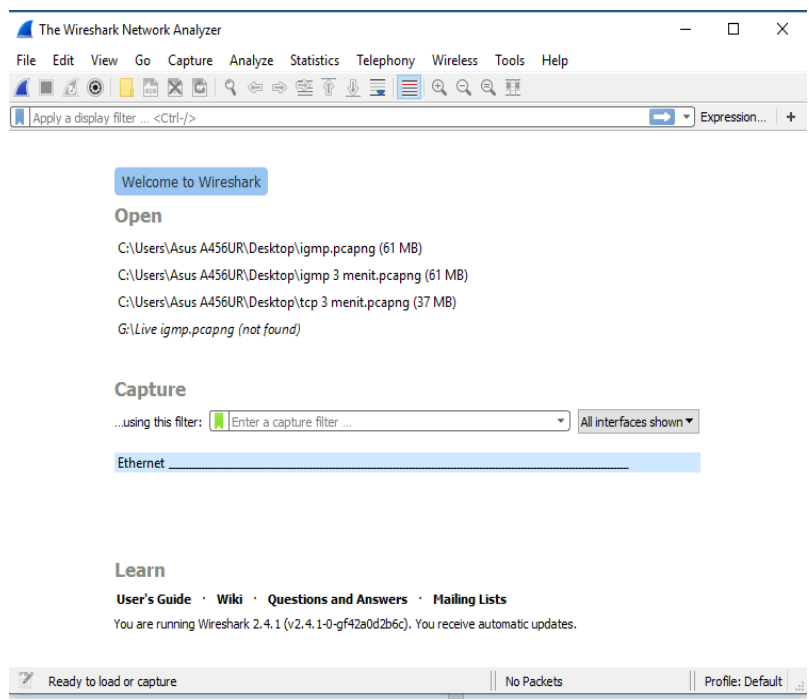

Gambar 10. Menu utama aplikasi wireshark

c. Beberapa saat kemudian akan muncul struktur wireshark

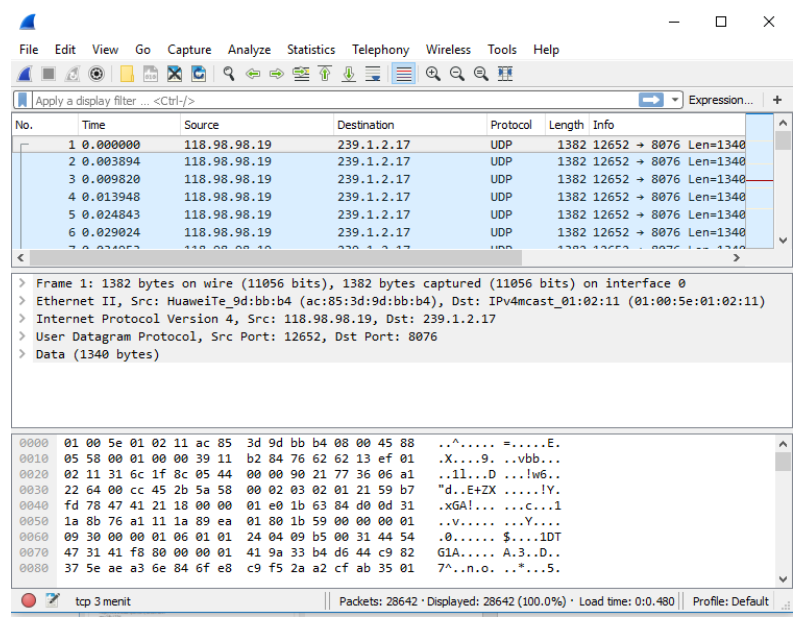

Gambar 11. Hasil capture data jaringan

d. Untuk mengetahui bahwa data tersebut IGMP maka di dalam Filter tool di ketik IGMP maka hasil data yang ditangkap oleh jaringan akan berubah menjadi IGMP.

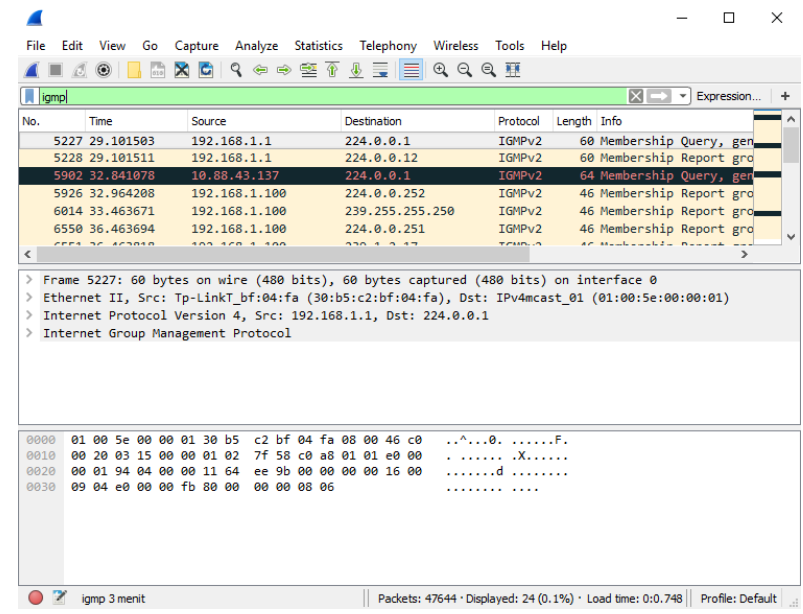

Gambar 10. Menentukan Protokol yang akan di capture

e. Untuk memulai capture cukup meng-klik tombol capture options, seperti gambar dibawah ini:

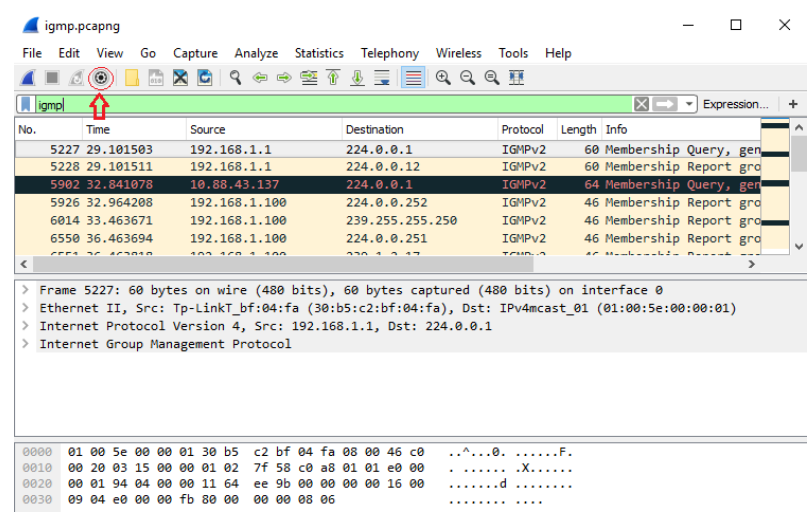

Gambar 11. Interface capture dalam protocol IGMP

f. Hasil capture yang muncul dapat disimpan dan dapat diubah dalam bentuk Ms. Excel.

\section{ANALISA DAN PEMBAHASAN}

Dalam analisa ini dilakukan pengamatan selama waktu tertentu yang kemudian akan dihitung jumlah bandwith yang dihasilkan, dapat dilihat di bawah ini:

Tabel 1. Hasil data dalam Protocol IGMP

\begin{tabular}{ccccccc}
$\begin{array}{c}\text { Time } \\
\text { (second })\end{array}$ & Source & Destination & Protocol & Leght & Bit & Kbps \\
\hline 29,1 & 192.168 .1 .1 & 244.0 .0 .12 & IGMPv2 & 60 & 480 & 16,49 \\
36,46 & 192.168 .1 .1 & 224.0 .0 .1 & IGMPv2 & 46 & 368 & 10,09 \\
92,84 & 192.168 .1 .100 & 224.0 .0 .251 & IGMPv2 & 64 & 512 & 5,51 \\
98,46 & 192.168 .1 .100 & 224.0 .0 .251 & IGMPv2 & 46 & 368 & 3,74 \\
152,83 & 10.88 .43 .137 & 244.0 .0 .1 & IGMPv2 & 64 & 512 & 3,35 \\
157,96 & 192.168 .1 .100 & 224.0 .0 .252 & IGMPv2 & 46 & 368 & 2,33 \\
\hline
\end{tabular}


Penjelasan data pada tabel 1 adalah sbb :

1. Time menunjukkan waktu yang diperoleh saat pengambilan data dimana dalam satuan detik (second).

2. Source adalah IP Address dari suatu perangkat yang mengirim paket sebanyak 32 bit.

3. Destination adalah tujuan IP Address dari perangkat yang akan menerima paket sebanyak 32 bit.

4. Protocol adalah menunjukkan untuk mengetahui protokol apa yang digunakan saat mengirim atau menerima paket. Tipe paket yang digunakan yaitu IGMPv2 (IGMP versi 2).

5. Length menunjukkan panjang frame dari paket, dimana satuan length ialah byte.

6. Bit adalah binary digital. Cara mencari nilai bit dengan rumus:

$$
\text { Bit }=\text { byte } x 8
$$

7. Kbps adalah hasil bandwith yang di dapat dari data live streaming.

$$
\text { Bandwith }=\frac{\text { bit }}{\text { Time }}
$$

Hasil dari perhitungan bandwith tersebut merupakan kecepatan membawa paket dalam satuan Kbps. Dari data yang di dapat dari alamat RTP 239.1.2.91:8520 dengan menggunakan software VLC Media Player dan wireshark protokol IGMP, bahwa dalam waktu tertentu terjadi perubahan byte dikarenakan tergantung pada waktu tersebut yang sedang sibuk dan pengambilan data dilakukan pada siang hari.

\section{KESIMPULAN}

Teknologi IPTV dapat mengirim video dalam suatu jaringan berbasis Internet Protocol (IP), kemudian dilakukan implementasi sebuah layanan IPTV berbasis protokol Internet Group Management Protocol (IGMP).

Paket yang dikirim sebanyak 32 bit dengan menggunakan jenis protokol yang digunakan IGMP versi 2 (IGMPv2). Panjang frame dari paket yang dikirimkan pada detik ke 92,84 dan 152,83 merupakan length terbanyak yaitu sebanyak 64 byte, namun nilai Kbps nya berbeda yaitu 5,51 dan 3,35 .

\section{DAFTAR PUSTAKA}

[1] A. Rahmadian, "Analisa Trafik IPTV pada Local Community Network menggunakan 802.11n," Universitas Indonesia, Jakarta, 2009.

[2] P. ZTE, "ZTE," 23 Mei 2014. [Online]. Available:http://wwwen.zte.com.cn/en/product s/access/msan/201405/t20140523 424188.ht $\underline{m l}$. [Diakses pada 30 September 2017].

[3] D. M. Cullough, "Awareness and IPTV," Entrisphere, Juli 2006. [Online]. Available: http://www.iec.org/newsletter/july06_2/broad band 1.ht. [Diakses pada September 2017].

[4] R. N. Michael Gibbs, "Riverstone Networks Advanced Technical Paper Series," Internet Group Management Protocol, 27 January 2003.

[5] AsianBriliant.com, "Pengertian Bandwith Dalam Jaringan Komputer dan Internet," 2011. [Online]. Available: http://www.asianbrilliant.com/main/pengertia n-bandwidth-dalam-jaringankomputer-daninternet-299.html. [Diakses pada September 2017].

[6] Z. Davis, "Definition of: Multicast," PC Mag Digital Group, [Online]. Available: https://www.pcmag.com/encyclopedia/term/47 441/multicast. [Diakses pada September 2017].

[7] D. Bombal, "HP Van SDN ControllerWireshark install and configuration," HP, HP Van SDN Controller, Open Flow, SDN, [Online].Available:https://www.pcmag.com/en cyclopedia/term/47441/multicast. [Dikases pada September 2017].

[8] Ataiko, "VLC Web Control Bar," 29042010. [Online].Available:http://atsiko.wordpress.co $\mathrm{m} / 2010 / 04 / 29 / v l c$-web-control-bar. [Diakses pada September 2017]. 